\title{
Effect of oral contraceptive pills on oxidative stress in Saudi women
}

\author{
Nadia N. Osman ${ }^{1,2}$, Dalal Mhammed Al-mutairi, ${ }^{1,3 *}$
}

\author{
Biochemistry Department, Faculty of Science, King Abdulaziz University, Jeddah, Saudi Arabia. \\ ${ }^{2}$ Food Irradiation Research Department, National Center for Radiation Research and Technology, Atomic Energy Authority, Cairo, Egypt. \\ ${ }^{3}$ Biochemistry Department, Faculty of Science, Tabuk University, Tabuk, Saudi Arabia. \\ *Correspondence to: Dalal Mhammed Al-mutairi (E-mail: dalal_9911@hotmail.com) \\ (Submitted: 05 January 2021 - Revised version received: 29 January 2021 - Accepted: 21 February 2021 - Published online: 26 April 2021)
}

\begin{abstract}
Objective The aim of this study was to evaluate the effect of oral contraceptive pills (OCPs) on oxidative stress in Saudi women.

Methods A total of 55 Saudi women were divided into two groups: users of OCP ( $N=30)$ for at least 1 year and non-users $(\mathrm{NOCP}, \mathrm{N}=25)$. The demographic data were obtained through face-to-face interviews performed by the researcher. Blood specimen from both groups were drawn after $8 \mathrm{~h}$ of fasting to estimate serum total antioxidant (TAOC), nitric oxide (NO), C-reactive protein (CRP), vitamins (E, B6, B12), and some hematological parameters: hemoglobin ( $\mathrm{Hb})$, red blood cell (RBC), white blood cell (WBC).

Results The results showed a significant decreased in serum $T A O C$, NO, vitamins $E$, and B6 accompanied with high significant increase in CRP level while no significant changes B12, HB, RBC, and WBC were observed in the OCP users as compared to the control group.

Conclusions The results of this study indicated that the use of OCP resulted in low levels of the total antioxidant, nitric oxide, vitamins $E$, and B6 with a significant increase in CRP. Women who used OCP may be more susceptible to oxidative stress by enhanced depletion of antioxidants.
\end{abstract}

\section{Introduction}

Uncontrolled pregnancy is one of the most important challenges of the century. ${ }^{1,2}$ Oral contraceptive pills (OCP) continued to be one of the most common methods of contraception used by the majority of women. Across all ages, women in their 20s are the most likely to use OCP. ${ }^{3}$

The OCP is the commonest contraceptive method used among Saudi women. ${ }^{4}$ Combined pills and progestin-only pills are the two types of OCP. ${ }^{5}$ The usage of OCP has been shown to cause oxidative stress by enhanced depletion of antioxidant and increased lipid peroxidation. ${ }^{6}$

Oxidative stress is defined as an imbalance between antioxidants and pro-oxidants in the cells, which are manifested by high levels of free radicals. ${ }^{7}$ Free radicals are deleterious to the human body because they can retrieve electrons from various molecules provoking the formation of oxidized forms so that severe oxidative stress can even trigger cell apoptosis and necrosis. ${ }^{8}$

Antioxidants systems, both non-enzymatic and enzymatic, are produced in the body to block too much free radicals production. ${ }^{9}$ Non-enzymatic antioxidants are known as synthetic antioxidants or dietary supplements, including vitamin $C$, vitamin E, $\beta$-carotene, and so on. ${ }^{10}$ Mounting evidence suggests that oxidative stress could play a pivotal role in the pathogenesis of several diseases including inflammatory, muscular, cardiovascular, and neurodegenerative diseases. ${ }^{11}$

Nitric oxide (NO) is a key organizer of the endothelia functional in the cardiovascular system. Change of the redox equilibrium in the vascular system intervenes with NO product and modifies vascular homeostasis bioavailability, promoting the development of metabolic and cardiovascular diseases. ${ }^{12}$ Estrogen generally has diverse vascular actions via increasing the bioavailability of NO on activation of NO synthase, and NO is inversely associated with oxidative stress. ${ }^{13}$ Lobysheva et al. ${ }^{14}$ observed a correlation between the use of combined oral contraceptives pills (COCP) and increased oxidative stress and the decreased $\mathrm{NO}$ in women who used OCP. Hassan et al. ${ }^{15}$ reported that NO is significantly reduced in COCP users than nonusers.

Vitamins also immediately scavenged ROS and upregulated the activity of antioxidant enzymes. Vitamin E is considered one of the most vital antioxidants; vitamin E prevent peroxyl radicals generated by peroxidation of polyunsaturated fatty as a result of ROS, therefore, protecting cells against oxidation of membrane phospholipids. ${ }^{16}$ Hassan et al. ${ }^{15}$ concluded that serum vitamin E levels are significantly lower among the OCP users' groups. Vitamins B6 and B12 play crucial inter-related roles in DNA synthesis throughout the lifecycle, especially during childhood, adolescence, and the reproductive years for women. ${ }^{17}$ Low vitamin $\mathrm{B} 6$ status has been associated with an increased risk of cardiovascular disease. ${ }^{18}$ The use of OCP causes many biochemical changes in; clotting factors, thrombosis, platelet changes, atherosclerosis, and inflammatory profiles. ${ }^{19-21}$ Jamil et al. ${ }^{22}$ concluded that hemoglobin levels are normal in the OCP users. Baker et al. (2016) reported that the WBC count elevates in the woman using OCP due to that the OCP may cause some internal infection in the women.

CRP is generated via the liver, and CRP levels rise within the presence of any inflammatory in the body. ${ }^{23}$ Serum levels of CRP are often used to detect inflammatory signs to estimate cardiovascular sickness and stroke. ${ }^{24}$ Ferreira et al. (2017) found a significant increase in CRP levels, especially among overweight women who use COCP more than $3 \mathrm{mg} / \mathrm{dL}$ (a boundary value related to the evolution of cardiovascular diseases). This study aimed to evaluate the effect of OCP on oxidative stress in Saudi women.

\section{Materials and Methods}

The study was carried out on 55 Saudi women were divided into two groups: women taking an OCP $(\mathrm{N}=30)$ and women who had never taken the OCP $(\mathrm{N}=25)$. The ethical approval was obtained through the local ethics committee at the King 
Abdul-Aziz University Hospital. All relevant information was recorded on predesign questionnaires. A blood specimen $(6 \mathrm{ml})$ was collected by venipuncture after $8-12 \mathrm{~h}$ of fasting were collected to estimate various parameters: total antioxidants, NO, vitamins E, B6, and B12 by colorimetric method using ELISA Kit. $\mathrm{Hb}, \mathrm{RBC}$, and $\mathrm{WBC}$ were estimated using a hematology analyzer. The CRP level was also determined by a commercial Kit from SIMENS.

Statistical Package for Social Science (SPSS) computer software was used for data analysis. Means \pm standard deviation (SD) was calculated. Independent $t$-test and Spearman's correlation were used to analyze the differences between bath OCP users and non-user control. The results were considered statistically significant at $\mathrm{p} \leq 0.05$.

\section{Results}

The current results showed that total antioxidant and nitric oxide were significantly decreased $(p=0.000)$ among women using oral contraceptive when compared to control group (Table 1).

As shown in Table 2, there was a highly significant $(\mathrm{p}=0.000)$ reduction in the vitamins $\mathrm{E}$ and $\mathrm{B} 6$ in OCP users compared to the control group. However, there was no significant difference $(\mathrm{p}=0.32)$ in vitamin B12 between the cases and control.

Data demonstrated in Table 3 showed that OCP induced a non-significant changes in $\mathrm{Hb}, \mathrm{RBC}$, and $\mathrm{WBC}(\mathrm{p}=0.06,0.52$, 0.90 respectively), associated with a highly significant increase ( $\mathrm{p}=0.000)$ in CRP, compared to NOC.

From Table 4, it could be observed that there was a significant changes association between duration of OCP use and TAOC, NO, CRP, vitamins E, and B6. Moreover, $\mathrm{Hb}$ was

Table 1. The effect of $\mathbf{0 C P}$ on Total antioxidant and NO.

\begin{tabular}{lccccc}
\hline Variables & Group & N & Mean & p-value & Sig \\
\hline \multirow{2}{*}{ TAOC } & NOC & 25 & 21.82 & & \\
& OCP & 30 & 4.89 & 0.000 & H.Sig \\
\multirow{2}{*}{ NO } & NOC & 25 & & & \\
& OCP & 30 & 22.05 & 0.000 & H. Sig \\
\hline
\end{tabular}

NOC non-oral contraceptives, OCP oral contraceptives pills, TAOC total antioxidant, $\mathrm{NO}$ nitric oxide.

Values are as Mean $\pm \mathrm{SD}, \mathrm{p}<0.05$ significant as compared to the non-users.

Table 2. The effect of OCP on vitamins.

\begin{tabular}{lccccc}
\hline Variables & Group & N & Mean & p-value & Sig \\
\hline Vitamin E & NOC & 25 & & & \\
& OCP & 30 & 24.379 .87 & 0.000 & H. Sig \\
Vitamin B6 & NOC & 25 & 627.65123 .38 & & \\
& OCP & 30 & 274.1870 .24 & 0.000 & H. Sig \\
& NOC & 25 & 267.4867 .05 & & \\
Vitamin B12 & OCs & 30 & 248.46 & 0.32 & N. Sig \\
& & & & \\
\hline
\end{tabular}

NOC non-oral contraceptives, OCP oral contraceptives pills.

Values are as Mean $\pm S D, p<0.05$ significant as compared to the non-users.
Table 3. The effects of $\mathbf{O C P}$ on Some Hematological Parameters and CRP.

\begin{tabular}{lccccc}
\hline Variables & Group & N & Mean & p-value & Sig \\
\hline Hb & NOC & 25 & & 0.06 & N. Sig \\
& OCP & 30 & 12.161 .77 & & \\
RBC & NOC & 25 & 4.320 .58 & 0.52 & N. Sig \\
& OCP & 30 & 4.230 .42 & & \\
WBC & NOC & 25 & 6.991 .73 & 0.90 & N. Sig \\
& OCP & 30 & 7.083 .59 & & \\
CRP & NOC & 25 & 0.16 & 0.000 & H. Sig \\
& OCP & 30 & & & \\
\hline
\end{tabular}

NOC non-oral contraceptives, OCP oral contraceptives pills, HB haemoglobin, $\mathrm{RBC}$ red blood cells, WBC white blood cells, CRP C-reactive protein. Values are as Mean $\pm S D, p<0.05$ significant as compared to the non-users.

significantly higher started after 5 years, while, vitamin B12 and WBC were significantly different started 3-4 years. No significant differences in the $\mathrm{RBC}$ were noticed along with the tested duration (1-7 years) (Table 4 ).

\section{Discussion}

Oral contraceptive steroids are one of the factors that enhance oxidative stress and lead to the formation of free radicals. Oxidative stress constitutes a disturbance caused by an imbalance between the generation of free radicals and the antioxidant system, which causes damage to biomolecules. This, in turn, may lead to the occurrence of many chronic degenerative diseases. $^{25}$

The free radical-mediated peroxidation of membrane lipids increases permeability and membrane fluidness with loss of its integrity that leads to cell damage. ${ }^{26}$ Antioxidants work cooperatively in biological systems, and it is important to be able to correlate antioxidant measurements with antioxidant defenses and disease prevention. It is therefore recommended to study "total antioxidant capacity", rather than monitoring individual antioxidant levels, which may be less affected by dietary habits. ${ }^{27}$ In this study, the total antioxidant level was significantly decreased among women using OCP. This result was in agreement with Palan et al. (2010) and Adejumo et al. ${ }^{28}$ The behavior of molecules related to oxidative stress can differ according to types and doses of estrogen, progestogen, or the particular compounds of estrogen and progestogen. ${ }^{29}$

Estrogens display an antioxidant activity by inhibiting the expression and function of the NADP+/NADPH oxidase, ${ }^{30}$ by increasing the expression and level of activation of the endothelial isoform of the nitric oxide synthase (eNOS) ${ }^{31}$ and by stimulating the expression and activity of the manganese SOD (MnSOD) and of the extracellular SOD (ecSOD). ${ }^{32}$ These antioxidant activities of estrogens are counteracted by progestins via the activation of the NADPH oxidase and the inhibition of the expression and activity of the MnSOD and of the ecSOD. ${ }^{33}$ Therefore it implies that the counteractive effect of progestin would result in a decrease in the serum total antioxidant status especially, in women taking either COCP. ${ }^{28}$

In the current study, there is a significant decrease in serum NO in the OCP users as compared to the control group. 


\begin{tabular}{|c|c|c|c|c|}
\hline & \multirow{2}{*}{$\begin{array}{l}\text { Control } \\
N=25\end{array}$} & \multicolumn{3}{|c|}{ Duration of $\mathrm{OCs}$} \\
\hline & & $\begin{array}{c}1-2 \text { years } \\
n=7\end{array}$ & $\begin{array}{c}3-4 \text { years } \\
n=10\end{array}$ & $\begin{array}{c}5-7 \text { years } \\
n=13\end{array}$ \\
\hline TAOC & $21.828 \pm 5.674$ & $\begin{array}{c}5.357 \pm 1.651 \\
P=0.000^{*}\end{array}$ & $\begin{array}{c}4.860 \pm 1.706 \\
P=0.000^{*}\end{array}$ & $\begin{array}{c}4.669 \pm 2.200 \\
P=0.000^{*}\end{array}$ \\
\hline NO & $171.316 \pm 34.8$ & $\begin{array}{c}45.771 \pm 21.229 \\
P=0.000^{*}\end{array}$ & $\begin{array}{c}41.220 \pm 25.322 \\
P=0.000^{*}\end{array}$ & $\begin{array}{c}40.892 \pm 21.422 \\
P=0.000^{*}\end{array}$ \\
\hline CRP & $0.160 \pm 0.071$ & $\begin{array}{c}1.614 \pm 0.467 \\
P=0.000^{*}\end{array}$ & $\begin{array}{c}1.440 \pm 0.384 \\
P=0.000^{*}\end{array}$ & $\begin{array}{c}1.608 \pm 0.528 \\
P=0.000^{*}\end{array}$ \\
\hline Vit E & $96.524 \pm 25.026$ & $\begin{array}{c}23.843 \pm 11.652 \\
P=0.000^{*}\end{array}$ & $\begin{array}{c}22.460 \pm 8.921 \\
P=0.000^{*}\end{array}$ & $\begin{array}{c}26.139 \pm 10.081 \\
P=0.000^{*}\end{array}$ \\
\hline Vit B6 & $627.652 \pm 123.389$ & $\begin{array}{c}284.343 \pm 69.892 \\
P=0.000^{*}\end{array}$ & $\begin{array}{c}289.060 \pm 92.414 \\
P=0.000^{*}\end{array}$ & $\begin{array}{c}257.262 \pm 50.212 \\
P=0.000^{*}\end{array}$ \\
\hline Vit B12 & $267.480 \pm 67.053$ & $\begin{array}{c}278.00 \pm 50.471 \\
P=0.523\end{array}$ & $\begin{array}{c}224.300 \pm 70.539 \\
P=0.049^{*}\end{array}$ & $\begin{array}{c}251.154 \pm 85.517 \\
P=0.508\end{array}$ \\
\hline HB & $11.204 \pm 2.054$ & $\begin{array}{c}11.450 \pm 2.441 \\
P=0.600\end{array}$ & $\begin{array}{c}12.019 \pm 1.125 \\
P=0.547\end{array}$ & $\begin{array}{c}12.657 \pm 1.760 \\
P=0.047^{*}\end{array}$ \\
\hline RBC & $4.321 \pm 0.588$ & $\begin{array}{c}4.134 \pm 0.360 \\
P=0.218\end{array}$ & $\begin{array}{c}4.234 \pm 0.260 \\
P=0.371\end{array}$ & $\begin{array}{c}4.289 \pm 0.555 \\
P=0.712\end{array}$ \\
\hline WBC & $7.156 \pm 1.604$ & $\begin{array}{c}6.370 \pm 1.382 \\
P=0.210\end{array}$ & $\begin{array}{c}5.729 \pm 0.811 \\
P=0.008^{*}\end{array}$ & $\begin{array}{c}6.869 \pm 1.673 \\
P=0.470\end{array}$ \\
\hline
\end{tabular}

The values are the mean \pm S.D. of parameters measured

Significantly different from control value at $p<0.05^{*}, 0.01^{* *}, 0.001^{* * *}$

A similar result was reported by Lobysheva et al. ${ }^{14}$ Hassan et al. ${ }^{15}$ observed that taking COCP resulted in a significant decrease in NO level. Estrogen is generally has diverse vascular actions via increasing the bioavailability of $\mathrm{NO}$ on activation of NO synthase, and NO is inversely associated with oxidative stress. ${ }^{13}$ Decreased bioavailability of NO may result in abnormal reactions between the vessel wall and platelets and is thus involved in the initiation and progression of atherosclerosis. ${ }^{34}$

The present study reported a significant decrease in vitamins $\mathrm{E}, \mathrm{B} 6$ and no significant change in $\mathrm{B} 12$ in the OCP users as compared to the control group. A similar result was reported by Palan et al. (2010), Wilson et al. (2011) and Singh et al. (2018). The study by Hassan et al., ${ }^{15}$ observed a decrease in the serum vitamin E, especially in women taking either COCP. In contrast to our results, Mcarthur et al. (2013) and Berenson and Rahman, ${ }^{35}$ have reported that the young women using OCP had significantly lower serum vitamin B12 concentrations.

Vitamin E level was significantly decreased among women using OCP. The mechanism of such an effect is unknown, but it was thought that, at its high level, certain estrogens, in particular diethylstilbestrol, may produce reactive oxygen species that may attack a number of biological substances, including lipids and DNA, and could natural antioxidants may be consumed to trap such compounds. ${ }^{36}$ The OCP may have some relatively specific effect on tryptophan's metabolism, which is independent of vitamin B6 levels. This effect may be primarily on the activity of tryptophan oxygenase since studies in rats have shown directly as well as adrenal-mediated effects of estrogens on the activity of this enzyme. ${ }^{37}$ Previous studies $^{38,39}$ indicated that steroids or steroid conjugates could affect the activity of the PLP-dependent enzymes of the kynurenine pathway, i.e., kynureninase and kynurenine aminotransferase. Thus, it seems most likely that the altered tryptophan metabolism of oral contraceptive users is the summation of hormonal effects on tryptophan oxygenase and kynureninase rather than the production of a general vitamin B6 deficiency. ${ }^{40.41}$ Vitamin B12 level was no significant difference between OCP users and nonusers because that absorption is not affected and that redistribution of B12 throughout the body could be responsible. ${ }^{42}$

In this study, level $\mathrm{Hb}$ and $\mathrm{WBC}$ were showed a non-significant decrease in non-oral contraceptive users. Regarding hematological parameters, different results were observed by several researchers. Toryila et al. ${ }^{43}$ have reported a reduction in $\mathrm{Hb}, \mathrm{RBC}, \mathrm{WBC}$ among women using $\mathrm{COCP}$ compared to the controls. Jamil et al. ${ }^{22}$ showed $\mathrm{Hb}$ levels are normal in the OCP. Al-Zayadi ${ }^{44}$ and Yeasmin et al. ${ }^{45}$ have reported increases in $\mathrm{Hb}$ level comparing with control groups. Toryila et al. ${ }^{46}$ observed an increase in WBC count in COC-treated female Wistar rats. The difference may be as a result of the use of different COC with different concentrations of estrogen and progesterone and the duration of use. Mooij et al. (1992) reported no significant difference on hematological parameters due to OCP use in women, but serum iron status was significantly increased for the users of OCP.

In this study a no significant change in $\mathrm{RBC}$ among women using OCP. A similar result was reported by Al-Zayadi. ${ }^{44}$ Due to the confounding of the effects of dose and the type of hormone, and the formulation of the drug, it was not easy to estimate the effect of OCP on RBC. Even though the combination of estrogen and progesterone would be considered as advance formal of the OCP, the use of it still strongly associated with vascular disease. ${ }^{47}$ 
The results indicated a significant increase in CRP in the OCP users as compared to the control group; this finding is in agreement with Divani et al. ${ }^{48}$, Ferreira et al., (2017), Guedes et al. $^{49}$, and Oliveira et al. $^{50}$ It was indicating that OCP leads to an increased subclinical inflammatory process. Divani et al. ${ }^{51}$ established that progestin increases interleukin 6 (IL-6, an inflammatory-mediated stimulation) of CRP in combination with conjugated equine estrogen and showed that IL- 6 change was negatively linked to CRP change when subjects were treated only with equine estrogen. The involvement of progestin has been suggested to induce IL-6-mediated CRP stimulation, whereas other mechanisms are likely to be responsible for the development of CRP in women receiving only conjugated equine estrogen. ${ }^{52}$

This study evaluates the effects of duration of OCP use on oxidative stress, which is represented by a significant decrease in TAOC, NO, vitamins E, and B6 levels. In contrast, CRP has shown a significant increase. Egoro et al. (2018) demonstrated that elevated levels of plasma CRP in long-term users of OCs containing lower doses of estrogen and progestin composition for $\geq 2$ years as compared to (control group). However, it was observed a significant change in $\mathrm{Hb}, \mathrm{WBC}$, and B12 after 3 years of using OCP. Similarly, Toryila et al. $^{43}$ reported that long- term use of COCP might lead to more complications than short- time use. However, the long-term users of the OCP on $\mathrm{RBC}$ has shown no significant difference $(\mathrm{p} \geq 0.05)$ compared to the mean value of non-users of OCs (control group).

\section{Conclusion}

The results of this study indicated that the use of OCP resulted in low levels of total antioxidant, $\mathrm{NO}$, vitamins $\mathrm{E}$, and $\mathrm{B} 6$ with a significant increase in CRP. Moreover, there is a statistically significant relationship between OCP use and increased oxidative stress.

\section{Conflict of Interest}

None

16. Morganti, P, Bruno, C, Guarneri, F, Cardillo, A, Del Ciotto, P, Valenzano, F. Role of topical and nutritional supplement to modify the oxidative stress. Int J Cosmetic Sci, 2002;24:331-339.

17. Mann, J, Truswell, AS. Essentials of human nutrition, Oxford University Press. 2017.

18. Shen, J, Lai, C-Q, Mattei, J, Ordovas, JM, Tucker, KL. Association of vitamin B-6 status with inflammation, oxidative stress, and chronic inflammatory conditions: the Boston Puerto Rican Health Study. Am J Clin Nutr, 2010;91:337-342.

19. Haarala, A, Eklund, C, Pessi, T, Lehtimäki, T, Huupponen, R, Jula, A, Viikari, J, Raitakari, O, Hurme, M. Use of combined oral contraceptives alters metabolic determinants and genetic regulation of $\mathrm{C}$-reactive protein. The Cardiovascular Risk in Young Finns Study. Scand J Clin Lab Investig, 2009;69:168-174

20. Wiegratz, I, Stahlberg, S, Manthey, T, Sänger, N, Mittmann, K, Palombo-Kinne, E, Mellinger, U, Lange, E, Kuhl, H. Effects of an oral contraceptive containing 30 mcg ethinyl estradiol and 2 mg dienogest on lipid metabolism during 1 year of conventional or extended-cycle use. Contraception, 2010;81:57-61.

21. Sitruk-Ware, R, Nath, A. Characteristics and metabolic effects of estrogen and progestins contained in oral contraceptive pills. Best Pract Res Clin Endocrinol Metab, 2013;27:13-24.

22. Jamil, S, Khan, RA, Dilshad, H, Fatima, S. Haematologic variations associated with the long term use of contraceptives in young females. Int J Med Res Rev, 2014;2:580-586.

23. Bastard, J-P, Maachi, M, Lagathu, C, Kim, MJ, Caron, M, Vidal, H, Capeau, J, Feve, B. Recent advances in the relationship between obesity, inflammation, and insulin resistance. Eur Cytokine Network, 2006;17:4-12.

24. Zieske, AW, Tracy, RP, McMahan, CA, Herderick, EE, Homma, S, Malcom, GT, McGill JR, HC, Strong, JP. Elevated serum C-reactive protein levels and advanced atherosclerosis in youth. Arterioscl Thrombosis Vasc Biol, 2005:25:1237-1243

25. Aguilar, TAF, Navarro, BCH, Perez, JAM. Endogenous antioxidants: a review of their role in oxidative stress. A master regulator of oxidative stress-the transcription factor nrf2. 2016.

26. Abdoljalal, M, Gholamreza, V, Mohammad, T. Serum lipid peroxidtion nd leptin level in $\mathrm{ml}$ end female type 2 diabetic patients in Gorgan, Iran. J Chin Clin Med, 2010;5:26-35.

27. Lands, LC, Grey, V, Grenier, C. Total plasma antioxidant capacity in cystic fibrosis. Pediat Pulmonol, 2000;29:81-87.

28. Adejumo, EN, Adediji, IO, Akinmulero, AO. Effect of hormonal contraceptives on the total antioxidants status of women from Isolo, Lagos State, Nigeria. J Biosci Med, 2016:4:107.

29. Chen, J-T, Kotani, K. Different effects of oral contraceptive and dydrogesterone treatment on oxidative stress levels in premenopausal women. J Clin Med Res, 2018;10:146.

15. Hassan, AS, Al-Salih, RM, Al-Naser, AH. Long term oral contraceptive administration is associated with low serum levels of nitric oxide, vitamin C and vitamin E. Ind J Public Health Res Dev, 2020;11:1514-1519. 
30. Laufs, U, Adam, O, Strehlow, K, Wassmann, S, Konkol, C, Laufs, K, Schmidt, W, Böhm, M, Nickenig, G. Down-regulation of Rac-1 GTPase by estrogen. J Biol Chem, 2003;278:5956-5962.

31. Chambliss, KL, Shaul, PW. Estrogen modulation of endothelial nitric oxide synthase. Endocr Rev, 2002;23:665-686.

32. Strehlow, K, Rotter, S, Wassmann, S, Adam, O, Grohe, C, Laufs, K, Böhm, M, Nickenig, G. 2003. Modulation of antioxidant enzyme expression and function by estrogen. Circul Res, 2003;93:170-177.

33. Wassmann, K, Wassmann, S, Nickenig, G. 2005. Progesterone antagonizes the vasoprotective effect of estrogen on antioxidant enzyme expression and function. Circul Res, 2005;97:1046-1054

34. Fallah, S, Nouroozi, V, Seifi, M, Samadikuchaksaraei, A, Aghdashi, EM. Influence of oral contraceptive pills on homocysteine and nitric oxide levels: as risk factors for cardiovascular disease. J Clin Lab Anal, 2012;26:120-3.

35. Berenson, $A B$, Rahman, $M$. Effect of hormonal contraceptives on vitamin B12 level and the association of the latter with bone mineral density. Contraception, 2012;86:481-487.

36. Roy, D, Kalyanaraman, B, Liehr, JG. Xanthine oxidase-catalyzed reduction of estrogen quinones to semiquinones and hydroquinones. Biochem Pharmacol, 1991:42:1627-1631.

37. Braidman, IP, Rose, D. Effects of sex hormones on three glucocorticoidinducible enzymes concerned with amino acid metabolism in rat liver. Endocrinology, 1971:89:1250-1255.

38. Mason, M, Manning, B. Effects of steroid conjugates on availability of pyridoxal phosphate for kynureninase and kynurenine aminotransferase activity. Am J Clin Nutr, 1971;24:786-791.

39. Rose, D, Brown, R. The influence of sex and estrogens on liver kynureninase and kynurenine aminotransferase in the rat. Biochim Biophys Acta, 1969:184:412-419.

40. Lumeng, L, Cleary, RE, Li, T-K. Effect of oral contraceptives on the plasma concentration of pyridoxal phosphate. Am J Clin Nutr, 1974:27:326-333.

41. Rios-Avila, L, Coats, B, Chi, Y-Y, Midttun, Ø, Ueland, PM, Stacpoole, PW, Gregory III, JF. Metabolite profile analysis reveals association of vitamin B-6 with metabolites related to one-carbon metabolism and tryptophan catabolism but not with biomarkers of inflammation in oral contraceptive users and reveals the effects of oral contraceptives on these processes. $J$ Nutr, 2015;145:87-95
42. Wertalik, LF, Metz, EN, Lobuglio, AF, Balcerzak, SP. Decreased serum B 12 levels with oral contraceptive use. Jama, 1972:221:1371-4.

43. Toryila, J, Amadi, K, Odeh, S, Egesie, U, Adelaiye, A, Achie, L. Effects of combined oral contraceptive (Duofem) on some physiological parameters in female Wistar rats. J Afr Assoc Physiol Sci, 2018;6:65-72.

44. Al-Zayadi, T. Contraceptive effects in hematological and biochemical parameters of healthy women at Al- Samawah city. J Chem Biol Phys Sci, 2018;8.

45. Yeasmin, T, Haque, S, Yeasmin, S, Amin, M. Iron status in women using oral contraceptives. Bangl J Physiol Pharmacol, 2014;26.

46. Toryila, J, Amadi, K, Odeh, S, Adelaiye, A, UG, E, NA. Dynamics of combined oral contraceptive: a study of some haematological parameters in female wistar rats. IOSR J Pharm (IOSRPHR), 2014:4:15-19.

47. Durand, P, Blache, D. Enhanced platelet thromboxane synthesis and reduced macrophage-dependent fibrinolytic activity related to oxidative stress in oral contraceptive-treated female rats. Atherosclerosis, 1996;121:205-216.

48. Divani, AA, Luo, X, Datta, YH, Flaherty, JD, Panoskaltsis-Mortari, A. Effect of oral and vaginal hormonal contraceptives on inflammatory blood biomarkers. Mediat Inflam, 2015a.

49. Guedes, JVM, Nunes, NR, Ferreira, LG, Vilar, TG, Pinheiro, MB, Domingueti, CP. Evaluation of lipid profile, high-sensitivity C-reactive protein and D-dimer in users of oral contraceptives of different types. Jornal Brasileiro de Patologia e Medicina Laboratorial, 2018;54:14-20.

50. Oliveira, SDS, Petto, J, Diogo, DP, Santos, ACND, Sacramento, MDSD, LADEIA, AMT. Plasma renin in women using and not using combined oral contraceptive. Int J Cardiovasc Sci, 2020;33:208-214.

51. Divani, AA, Luo, X, Datta, YH, Flaherty, JD, Panoskaltsis-Mortari, A. Effect of oral and vaginal hormonal contraceptives on inflammatory blood biomarkers. Mediat Inflam, 2015b;379501-379501.

52. Reuben, DB, Palla, SL, Hu, P, Reboussin, BA, Crandall, C, Herrington, DM Barrett-Connor, E, Greendale, GA. Progestins affect mechanism of estrogeninduced C-reactive protein stimulation. Am J Med, 2006;119:167. e1-167. e8.

53. Norouzi, V, Seifi, M, Fallah, S, Korani, M, Samadikuchaksaraei, A. Effect of oral contraceptive therapy on homocysteine and C-reactive protein levels in women: an observational study. Anatolian Journal of Cardiology/Anadolu Kardiyoloji Dergisi, 2011;11. 